\title{
Factors associated with group bullying and psychopathology in elementary school students using child-welfare facilities
}

This article was published in the following Dove Press journal:

Neuropsychiatric Disease and Treatment

7 April 2015

Number of times this article has been viewed

\author{
Jun Won Kim ${ }^{1,2}$ \\ KounSeok Lee ${ }^{3}$ \\ Young Sik Lee ${ }^{4}$ \\ Doug Hyun $\mathrm{Han}^{4}$ \\ Kyung Joon Min ${ }^{4}$ \\ Sung Hwan Song ${ }^{5}$ \\ $\mathrm{Ga} \mathrm{Na} \mathrm{Park}{ }^{6}$ \\ Ju Young Lee' \\ Jae Ock Kim ${ }^{5}$ \\ 'Division of Child and Adolescent \\ Psychiatry, Department \\ of Neuropsychiatry, College \\ of Medicine, Seoul National University, \\ Seoul, South Korea; ${ }^{2}$ Department \\ of Psychiatry, Graduate School, \\ Chung-Ang University, Seoul, South \\ Korea; ${ }^{3}$ Department of Psychiatry, \\ Samsung Medical Center, Seoul, South \\ Korea; ${ }^{4}$ Department of Psychiatry, \\ Chung-Ang University, College \\ of Medicine, Seoul, South Korea; \\ ${ }^{5}$ Department of Psychiatry, Gongju \\ National Hospital, Gongju, South \\ Korea; ${ }^{6}$ Department of Special \\ Education, Graduate School, Dankook \\ University, Jukjeon, South Korea
}

Correspondence: JaeOck Kim

Department of Psychiatry, Gongju

National Hospital, 623-21 Gobunti-ro,

Gongju-si, South Korea

$\mathrm{Tel}+82418505896$

Fax +82 4I 8532095

Email allkightkjo@gmail.com
Purpose: Low socioeconomic status is an important risk factor for child psychiatric problems. Low socioeconomic status is also associated with psychiatric problems later in life. We investigated the effects of group bullying on clinical characteristics and psychopathology in elementary school students using child-welfare facilities.

Methods: Three hundred and fifty-eight elementary school students using child-welfare facilities were recruited. The School Bullying Self Rating Questionnaire was used to assess group bullying. To evaluate related psychopathology, the Children's Problem-Behavior Screening Questionnaire, the Children's Depression Inventory, the Beck Anxiety Inventory, the Suicidal Ideation Questionnaire, Young's Internet Addiction Scale, and Conners-Wells' Adolescent Self-Report Scale were applied. Samples were classified according to school grade (lower or upper), and each group's characteristics were compared as they related to bullying victims versus non-victims.

Results: The prevalence rate of group bullying was $22 \%$ in the lower-grade group and $12 \%$ in the higher-grade group. Bullying victims in lower grades reported high somatization, depressive symptoms, Internet addiction, and attention deficit hyperactivity disorder tendencies, whereas those in upper grades reported cognitive problems, symptoms of depression and anxiety, suicidal ideation, Internet addiction, and attention deficit hyperactivity disorder tendencies. Somatization and depressive symptoms were significant predictors of bullying in the lower-grade group, and anxiety was a significant predictor of bullying in the upper-grade group.

Conclusion: This study demonstrated that elementary school students using child-welfare facilities might have an increased risk of being bullied and that bullying victims may have different psychopathologies depending on their ages.

Keywords: socioeconomic status, somatization, depression, anxiety

\section{Introduction}

Childhood and adolescence is a period of dynamic interpersonal relations, and one's experience during this period has a significant impact on character development. ${ }^{1}$ The period between the upper grades of elementary school and middle school, a transition period from childhood to adolescence, is particularly influential compared with other periods of life. Group bullying refers to repeated and intentional behavior in which one or more individuals, either stronger in physical strength or higher in rank, hurt or threaten another individual. Group bullying can manifest itself in different verbal and nonverbal forms, including exclusion from activities, refusing to talk, provoking a quarrel, name calling, pushing, and beating. ${ }^{2}$ Given that group bullying occurs more often during this period, this is likely an important period for the onset of the psychopathology related to group bullying. ${ }^{3}$ In addition, group bullying in 
childhood and adolescence has been shown to delay social development and reduce one's likelihood of social participation, eventually having a detrimental impact on one's social and professional prospects. ${ }^{4}$ These findings indicate that it is important to identify individuals at high risk of being victimized by peer bullying in advance and to provide them with protection. The South Korean government currently conducts screening using the Children's Problem-Behavior Screening Questionnaire (CPSQ) to obtain a broader understanding of problem behavior, psychopathology, and group bullying in elementary school students.

Researchers have investigated whether group bullying may help explain the increased incidence of suicides among children and adolescents. ${ }^{5}$ It has been reported that group bullying is a cause of behavioral problems, including depression, anxiety, and suicide-related events, and that bullying negatively affects academic achievement, physical development, social relations, and one's ability to react. ${ }^{6}$ These effects can contribute to psychiatric diseases such as adjustment disorder, depression, and anxiety disorders. ${ }^{1,6,7}$ A survey about group bullying among elementary school students in South Korea showed that $5.3 \%$ of students were victims of bullying, $7.2 \%$ were both victims and bullies, and $12 \%$ were bullies only. ${ }^{8}$ A separate study reported that $9 \%$ of children surveyed were victims, $1.6 \%$ were both victims and bullies, and 7\% were bullies only. ${ }^{9}$ Responses from these surveys demonstrate that the number of children and adolescents involved in group bullying is not inconsequential and that bullying may have a considerable impact on mental health.

Children with symptoms of depression and anxiety appear vulnerable to aggressive peers and are highly likely to be bullied..$^{10}$ Research by Nishina et a ${ }^{11}$ indicates that symptoms of depression and anxiety developed both before and after group bullying. It has also been observed that violent and aggressive behavior in children with conduct disorder excites bullies and leads to violence, and that the number of cases of conduct disorder increases among victims. ${ }^{12,13}$ Therefore, anxiety, depression, and conduct disorder can be both the cause and the consequence of group bullying. ${ }^{6}$

Psychiatric diseases, such as schizophrenia, mental retardation, attention deficit hyperactivity disorder (ADHD), and affective disorder, are highly correlated with low socioeconomic status (SES). ${ }^{14}$ Most children using child-welfare facilities have relatively low SES, with $38.2 \%$ belonging to a marginally poor class, $25 \%$ receiving National Basic Livelihood Security benefits, $22.9 \%$ qualifying for some form of state support, and $13.9 \%$ not receiving any benefits. ${ }^{15}$ According to a South Korean study, lowincome children had higher rates of depression and ADHD compared with a control group. ${ }^{16} \mathrm{~A}$ foreign study demonstrated that family income affected children's depressive symptoms and that frequent moves and changes in family structure were related to group bullying. ${ }^{17}$ Another study showed that low SES, poor maternal educational background, and belonging to a single-parent family were risk factors for ADHD. ${ }^{18}$ Children from low-SES families are prone to depression and ADHD, and such psychopathology is the cause and consequence of group bullying, causing a vicious cycle. ${ }^{6}$

The present study investigated the effects of group bullying on clinical characteristics and psychopathology. It focused on elementary school students using child-welfare facilities - such children were expected to be more vulnerable to mental health problems - and examined factors related to whether a person was bullied in a group setting; one hypothesis is that symptoms of depression and anxiety as well as other psychiatric problems are predictors of whether a person is bullied. Due to developmental differences between children and adolescents, this study classified the sample into two groups: elementary-school students in lower grades - and elementary-school students in upper grades - this relates to the second hypothesis: that there are significant psychopathological differences between lower- and upper-grade students associated with the risk of bullying.

\section{Materials and methods Sampling process}

This study surveyed elementary school children using child-welfare facilities, including orphanages, group homes, and community child centers, located in the Seosan and Hongseong areas of South Chungcheong Province, South Korea. We sent a letter explaining the aims and procedures of the study to the child-welfare facilities, headmasters, and classroom teachers. After the headmasters and teachers had given their consent, a sealed letter explaining the aims and procedures of the study was given to each child to give to his or her parents. The students and their guardians received an explanation of the purpose of this study and the guaranteed anonymity of the survey findings, which were to be used exclusively for research purposes, and signed a written agreement. This study surveyed 358 elementary school students, who were divided into lower graders (between the ages of 6 and 9 years) and upper graders (between the ages of 10 and 12 years). All of the participants completed a questionnaire related to basic demographic information, including years of 
education, history of mental diseases, and number of family members with whom they lived. All of the participants also completed the School Bullying Self Rating Questionnaire (SBSRQ), the CPSQ, Conners-Wells' Adolescent SelfReport Scale - Short Form (CASS-S), and Young's Internet Addiction Scale (IAS). Additionally, the Children's Depression Inventory (CDI) was administered to lower graders, and the Beck Anxiety Inventory (BAI) and Suicidal Ideation Questionnaire (SIQ) were administered to upper graders. The BAI and SIQ could not be completed by lower graders, who were younger than the appropriate age range for these instruments. This study was approved by the Institutional Review Board of Gongju National Hospital.

\section{Evaluation tools SBSRQ}

The SBSRQ is part of series of questionnaires published in 2007 by the Seoul Child Adolescent Mental Health Center to examine mental health. This self-report questionnaire includes 12 items related to one's experience of harassment and close peer relationships, and is used to assess group bullying at school. ${ }^{19}$ Items such as "I have been threatened or blackmailed by other students at school" and "I have no close friends at school" are rated on a four-point Likert scale from 1 (not at all) to 4 (strongly agree). In this study, Cronbach's $\alpha$ for the SBSRQ was 0.94 .

\section{CPSQ}

The CPSQ consists of 26 items, including five items on internalization, three items on cognition, two items on drug abuse, six items on physical health, and ten items on externalization (including three items on ADHD, four items on oppositional defiant disorder, and three items on conduct disorder). Each question is rated on a four-point Likert scale from 0 (not at all) to 3 (strongly agree). Due to the standardization of the large-scale sampling of children, the CPSQ has demonstrated high Cronbach's $\alpha$ (parents: 0.85, teachers: 0.85) and interrater reliability. ${ }^{20}$

\section{CDI}

The CDI is a self-report measure developed by Kovacs and Beck to evaluate depressive symptoms in childhood. Originally adapted from the Beck Depression Inventory, the CDI is a scale suitable for children aged 7 to 17 years. Twenty-seven items are graded in severity from 0 to 2 , with higher scores indicating greater problems. This study used the version of the CDI translated by Cho and Lee. ${ }^{21}$ In this study, Cronbach's $\alpha$ for the CDI was $0.88 .{ }^{21}$

\section{BAI}

The BAI, created by Beck et $\mathrm{al}^{22}$ to assess anxiety, is a 12 -item self-report inventory. The items are rated on a scale from 0 to 3 , with total scores ranging from 0 to 63 . Higher scores indicate higher severity. ${ }^{23}$ In this study, Cronbach's $\alpha$ for the BAI was $0.91 .^{24}$

\section{SIQ}

The SIQ is a self-report measure developed by Reynolds ${ }^{25}$ to measure suicide risk. Thirty items are graded in severity from 0 to 5, with total scores ranging from 0 to 150 . Higher scores indicate a higher risk of suicidal ideation (Shin, unpublished data, 1992). In this study, Cronbach's $\alpha$ for the SIQ was $0.95 .{ }^{26}$

\section{IAS}

The IAS is a 20 -question inventory developed by Young ${ }^{27}$ at the Center for On-line Addiction. Each question is rated on a scale from 1 to 5 , with higher scores indicating more severe problems. The IAS classifies respondents into three groups: average Internet users (scores under 50), individuals with Internet-related problems (scores between 50 and 79), and individuals with obvious problems stemming from Internet use (scores of 80 or higher). In this study, Cronbach's $\alpha$ was 0.94 .

\section{CASS-S}

The CASS-S, created by Conners for the assessment of ADHD, was adapted by Bahn et $\mathrm{al}^{28}$ and translated into Korean. The credibility and validity of the scale were verified. Twenty-seven items are graded on a scale from 1 to 4 , with higher scores indicating a higher risk of ADHD. In this study, Cronbach's $\alpha$ for the CASS-S was $0.88 .{ }^{28}$

\section{Statistical analysis}

The survey group was divided into elementary-school lower graders and upper graders. This study also classified participants into two groups: a bullying-victims group, consisting of participants who responded to more than two items on the SBSRQ with "strongly agree", and who were thus likely to be bullied; and a normal group. To compare demographic characteristics and psychopathology between lower and upper graders according to whether one was bullied, independentsample $t$-tests, chi-square tests, and Fisher's exact tests were performed. Additionally, in an effort to examine causes of group bullying, binary logistic regression was conducted, with measures showing a significant difference between groups as independent variables, and whether one was bullied 
as the dependent variable. All of the analyses were conducted using PASW 18.0.0 for Windows (SPSS Inc., Chicago, IL, USA), with a significance level of $P<0.05$.

\section{Results}

\section{Demographic characteristics}

Three hundred and fifty-eight students (159 lower graders and 199 upper graders) participated in this study. There were no significant differences in demographic characteristics between participants who had been bullied and those who had not. Additionally, no significant differences were found in mental health history between these groups. Although victims of bullying are known to be vulnerable to mental illness and may need treatment, that was not the case in this sample..$^{710,11}$ There were also no significant differences between the two groups with respect to the total number of family members or the number of family members living together (see Table 1).

\section{Psychopathology}

In the lower graders, the bullying victims group showed significantly higher scores than the normal group not only on the CPSQ physical health $(P=0.009)$ and total scores $(P=0.008)$, but also on the IAS ( $P=0.014)$, CASS-S $(P=0.002)$, and CDI $(P=0.001)$. In addition, there were no significant differences on the CPSQ physical health score between the two groups. In the upper graders, the bullying victims group showed significantly higher scores than the normal group on the CPSQ cognitive scale $(P=0.044)$, IAS $(P=0.025)$, CASS-S $(P<0.001)$, CDI $(P<0.001)$, BAI $(P<0.001)$, and SIQ $(P=0.026$; see Table 2$)$.

\section{Predictive factors of whether elementary school students using child-welfare facilities are bullied}

Lower graders with high scores for CPSQ physical health (odds ratio $[\mathrm{OR}]=1.43 ; 95 \%$ confidence interval $[\mathrm{CI}]$
$1.09-1.89 ; P=0.011)$ and the CDI $(\mathrm{OR}=1.09 ; 95 \% \mathrm{CI}$ $1.02-1.16 ; P=0.012$ ) were more likely to be bullied by peers. The CPSQ total score, IAS, and CASS-S were not statistically significant predictors of whether a person would be bullied (see Table 3). Upper graders with high scores on the BAI were more likely to be bullied by peers ( $\mathrm{OR}=1.12 ; 95 \%$ CI 1.01-1.25; $P=0.034)$. The CPSQ cognitive score, IAS, CASS-S, CDI, BAI, and SIQ were not statistically significant predictors of peer bullying (see Table 4).

\section{Discussion}

The purpose of this study was to examine differences in clinical characteristics and psychopathology associated with group bullying among elementary school students using child-welfare facilities.

The results indicated incidence rates of bullying by peers to be $22 \%$ in lower graders and $12 \%$ in upper graders. These rates are higher than previously reported combined incidence rates of being a victim and being both a victim and a bully, which were between $10 \%$ and $12 \% .{ }^{1,8}$ As mentioned previously, it can be surmised that higher rates of depression and conduct disorder in children of low SES using child-welfare facilities contribute to peer bullying among elementary school students. It may be the case that with increasing age, certain students - for example, underprivileged students and those who do not receive support from friends - tend to be victimized. ${ }^{29}$ This assumption explains why the incidence rate of being bullied decreases while the frequency of bullying either remains the same or increases. ${ }^{30}$ Because living with biological parents has been shown to be a protective factor, ${ }^{31}$ it was expected that the total number of family members or the number of family members living together would affect the incidence of peer bullying, but this was not the case. Rather than the number of family members, familyrelated characteristics, such as parents' antisocial behavior or child abuse, appear to affect peer bullying. ${ }^{32}$

Table I Means (standard deviation) and comparison of sociodemographic characteristics among bullying victim groups

\begin{tabular}{|c|c|c|c|c|}
\hline \multirow[t]{2}{*}{ Variable } & \multicolumn{2}{|c|}{ Lower grades } & \multicolumn{2}{|c|}{ Upper grades } \\
\hline & $\begin{array}{l}\text { Bullying } \\
(n=35)\end{array}$ & $\begin{array}{l}\text { Normal } \\
(n=124)\end{array}$ & $\begin{array}{l}\text { Bullying } \\
(n=24)\end{array}$ & $\begin{array}{l}\text { Normal } \\
(n=175)\end{array}$ \\
\hline Age (years) & $7.60 \pm 0.91$ & $7.90 \pm 1.01$ & $10.88 \pm 0.68$ & I I. $03 \pm 0.77$ \\
\hline \multicolumn{5}{|l|}{ Sex } \\
\hline Male & $19(54.3)$ & $64(51.6)$ & $7(29.2)$ & $77(44.0)$ \\
\hline Female & $16(45.7)$ & $60(48.4)$ & 17 (70.8) & $98(56.0)$ \\
\hline Years of education & $1.94 \pm 0.91$ & $2.28 \pm 1.06$ & $5.00 \pm 1.25$ & $5.28 \pm 0.88$ \\
\hline \multicolumn{5}{|l|}{ Psychiatric history } \\
\hline No & $33(94.3)$ & $123(99.2)$ & $22(91.7)$ & $172(98.3)$ \\
\hline Yes & $2(5.7)$ & $\mathrm{I}(0.8)$ & $2(8.3)$ & $3(1.7)$ \\
\hline Whole familya & $8.59 \pm 4.19$ & $9.11 \pm 4.33$ & $8.58 \pm 3.56$ & $10.17 \pm 4.85$ \\
\hline Living together as a family & $3.47 \pm 1.19$ & $3.16 \pm 1.15$ & $2.83 \pm 1.61$ & $3.35 \pm 2.06$ \\
\hline
\end{tabular}

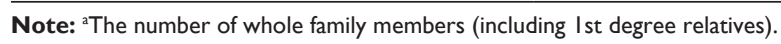


Table 2 Means (standard deviation) and comparison of neuropsychological measures among bullying victim groups

\begin{tabular}{|c|c|c|c|c|c|c|c|c|}
\hline \multirow[t]{2}{*}{ Variable } & \multicolumn{4}{|c|}{ Lower grades } & \multicolumn{4}{|c|}{ Upper grades } \\
\hline & $\begin{array}{l}\text { Bullying } \\
(n=35)\end{array}$ & $\begin{array}{l}\text { Normal } \\
(n=124)\end{array}$ & Hedges' g & $P$-value & $\begin{array}{l}\text { Bullying } \\
(n=24)\end{array}$ & $\begin{array}{l}\text { Normal } \\
(n=\mid 75)\end{array}$ & Hedges' g & $P$-value \\
\hline \multicolumn{9}{|l|}{ CPSQ } \\
\hline Internalizing & $2.6 I \pm 3.00$ & $1.76 \pm 2.18$ & 0.36 & 0.075 & $3.00 \pm 3.19$ & $2.32 \pm 2.75$ & 0.24 & 0.297 \\
\hline Externalizing & $5.91 \pm 4.75$ & $4.27 \pm 4.13$ & 0.38 & 0.054 & $7.19 \pm 6.13$ & $5.03 \pm 5.20$ & 0.40 & 0.082 \\
\hline Cognitive & $1.39 \pm 2.08$ & $0.86 \pm 1.59$ & 0.31 & 0.115 & $1.62 \pm 2.13$ & $0.60 \pm 1.29$ & 0.72 & 0.044 \\
\hline Drug abuse & $0.36 \pm 0.60$ & $0.28 \pm 0.63$ & 0.13 & 0.518 & $0.62 \pm 0.67$ & $0.45 \pm 0.72$ & 0.24 & 0.316 \\
\hline Physical health & $2.24 \pm 1.97$ & $1.24 \pm 1.36$ & 0.66 & 0.009 & $2.00 \pm 2.78$ & $1.64 \pm 2.04$ & 0.17 & 0.568 \\
\hline Sum $^{\mathrm{a}}$ & $12.58 \pm 10.46$ & $8.35 \pm 7.10$ & 0.53 & 0.008 & $14.33 \pm 12.25$ & $9.96 \pm 9.03$ & 0.46 & 0.127 \\
\hline IAS & $20.80 \pm 17.63$ & $12.61 \pm 13.06$ & 0.58 & 0.014 & $29.52 \pm 22.34$ & $18.03 \pm 15.39$ & 0.70 & 0.025 \\
\hline CASS-S & $24.91 \pm 15.65$ & $|5.60 \pm| 0.3 \mid$ & 0.79 & 0.002 & $28.50 \pm|| .23$ & $15.15 \pm 9.68$ & 1.35 & $<0.001$ \\
\hline CDI & $14.86 \pm 8.09$ & $9.33 \pm 6.59$ & 0.79 & 0.001 & $17.91 \pm 9.77$ & $8.40 \pm 6.99$ & 1.29 & $<0.001$ \\
\hline BAI & & & & & $15.93 \pm 9.44$ & $4.80 \pm 5.73$ & 1.77 & $<0.001$ \\
\hline SIQ & & & & & $30.07 \pm 33.65$ & $8.23 \pm 19.78$ & 1.00 & 0.026 \\
\hline
\end{tabular}

Note: aSum of all items on the CPSQ.

Abbreviations: BAI, Beck Anxiety Inventory; CASS-S, Conners-Wells' Adolescent Self-Report Scale - Short Form; CDI, Kovacs' Children's Depression Inventory; CPSQ, Children's Problem-Behavior Screening Questionnaire; IAS, Young's Internet Addiction Scale; SIQ, Suicidal Ideation Questionnaire.

With respect to psychopathological characteristics, there is a significant association between CPSQ physical health score and lower graders who were victims of bullying. Somatization means that a person has physical symptoms that cannot be explained based on general medical conditions, the direct effects of substance, or other mental diseases. In the case of children, somatization takes the form of a stomachache or headache. ${ }^{14}$ In the early stage of life, undifferentiated physical disorders can occur because it is difficult for young children to adequately express their emotions due to deficient motor and language abilities. However, as children grow, they are able to verbalize emotional pain, allowing them to eventually move past this condition. Negative early-life experiences, including trauma and deprivation, have been shown to lead to undifferentiated physical disorders. ${ }^{33}$ On this basis, it may be the case that victims of peer bullying return to an immature state and have somatization symptoms due to emotional pain. The regression analysis in this study revealed that lower graders with higher somatization scores

Table 3 Binary logistic regression analysis of the risk factors for bullying in children from low-income families in the lower grade elementary school group

\begin{tabular}{llllll}
\hline Variable* & Beta & SE & Wald & OR $(95 \% \mathrm{Cl})$ & $P$-value \\
\hline $\begin{array}{l}\text { CPSQ physical } \\
\text { problem }\end{array}$ & 0.36 & 0.14 & 6.54 & $\mathrm{I} .43(1.09-\mathrm{I} .89)$ & $0.01 \mathrm{I}$ \\
CASS-S & 0.03 & 0.02 & 2.83 & $\mathrm{I} .03(1.00-1.07)$ & 0.092 \\
CDI & 0.08 & 0.03 & 6.30 & $\mathrm{I} .09(1.02-1.16)$ & 0.012 \\
\hline
\end{tabular}

Note: *Variables with $P<0.05$ according to the univariate analysis were entered into the binary logistic regression analysis.

Abbreviations: CASS-S, Conners-Wells' Adolescent Self-Report Scale - Short Form; CDI, Kovacs's Children's Depression Inventory; Cl, confidence interval; CPSQ, Children's Problem-Behavior Screening Questionnaire; OR, odds ratio; $\mathrm{SE}$, standard error. tended to be more likely to be bullied. Older children are mature enough to verbalize their emotions, thus explaining why the two groups of upper graders did not show significant differences in somatization scores. More mature language skills may enable these children to express emotional pain such as anxiety and depression, reducing their dependence on extreme and nonverbal means of expression. ${ }^{34}$

In contrast to lower graders, the upper-grade bullying victims group showed significantly higher CPSQ cognitive scores than the normal group. The CPSQ score is based on items such "have low intelligence", "poorer at reading, writing, and calculating than peers", and "so slow in language development that conversation is affected". A previous study revealed that victims of bullying showed low academic achievement and were maladjusted to school. ${ }^{6}$ In contrast, a separate study indicated that low academic achievement was irrelevant to group bullying or was present in the bullying group, rather than the victims of bullying. ${ }^{35}$ However, taking into account the finding that low SES is associated with low levels of academic achievement and diminished cognitive function, along with social and behavioral problems, this study is important for understanding the characteristics of bullying victims. ${ }^{36}$

Table 4 Binary logistic regression analysis of risk factors for bullying in children from low-income families in the upper grade elementary school group

\begin{tabular}{llllll}
\hline Variable* & Beta & SE & Wald & OR $(95 \%$ Cl) & P-value \\
\hline CDI & 0.11 & 0.06 & 3.30 & I.12 (0.99-I.26) & 0.069 \\
BAI & 0.11 & 0.05 & 4.47 & $1.12(1.01-1.25)$ & 0.034 \\
\hline
\end{tabular}

Note: *Variables with $P<0.05$ according to the univariate analysis were entered into the binary logistic regression analysis.

Abbreviations: BAI, Beck Anxiety Inventory; CDI, Kovacs's Children's Depression Inventory; $\mathrm{Cl}$, confidence interval; $\mathrm{OR}$, odds ratio; $\mathrm{SE}$, standard error 
Bullying victims can be classified into two groups: passive victims, who are weak, are less popular, and have low confidence; and provocative victims, who are active and easily become upset. ${ }^{1}$ In this study, the significantly elevated CDI and CASS-S scores in the bullying victim groups among both lower and upper graders suggest that depression, ADHD, cognitive problems, and conduct problems are prevalent in victims of bullying. This finding is consistent with the results of a study by Choi et $\mathrm{al}^{1}$ which suggested: first, that because bullying victims have low self-resilience, they fail to adapt to stress and are met with criticism and rejection by peers because of unstable personal relationships; and second, that ADHD leads to a lack of focus and difficulty controlling impulses. In this study, elementary school students in childwelfare facilities exhibited the same psychopathological characteristics as those of passive and active bullying victims in studies of other elementary school students. The results of the regression analysis suggest that depression, as assessed by the CDI, is the only factor that can determine whether lower graders in elementary school are bullied. Therefore, depression must be considered when evaluating psychopathology related to group bullying among elementary school students using child-welfare facilities, particularly lower graders.

In addition, scores on the SIQ, a measure of suicidal ideation, were significantly elevated in the upper-grade bullying victims group. In general, depression is associated with an increased incidence of suicide. However, in the case of the bullying victims group, the prevalence of suicide is increased regardless of depression status. ${ }^{7}$ The reason for the depression-independent increase in suicide, according to a previous study, is that the impulsive behavior of bullying victims may facilitate suicide attempts and that group bullying can have a direct effect on suicidal ideation. ${ }^{37}$

In this study, one shared characteristic of bullying victims in both lower and upper graders was a significantly higher rate of Internet addiction. Previous research demonstrated that an Internet-addicted group suffered from depression, had low self-esteem, and was highly afraid of rejection; in addition, the study showed that a rise in Internet usage led to increased depression and loneliness. ${ }^{38}$ Considering that Internet addiction is a matter of impulse control, ${ }^{39}$ this study demonstrated that levels of depression and impulsiveness in the bullying victims group were elevated similar to those in an Internet addiction group and that bully victims could be characterized based on their Internet-related behavior. A study conducted by Choi et $\mathrm{al}^{40}$ demonstrated that children from economically underprivileged families were highly likely to be addicted to the Internet. Significantly elevated
CASS-S scores suggest that the bullying victims group had a tendency to suffer from ADHD. According to research on the relationship between ADHD and Internet addiction, children with ADHD have problems with behavioral inhibition and control, preventing them from controlling their use of the Internet on their own. ${ }^{41}$ Children with ADHD may also use the Internet to compensate for their lack of social skills and difficulties in personal relationships. ${ }^{42}$ Consequently, the bullying victims group, composed of children who suffered from depression and impulsiveness, also tended either to be addicted to the Internet or to suffer from ADHD.

Finally, the regression analysis of the upper graders demonstrated that BAI scores were the only factor that determined whether a child had been bullied. Because upper graders have more mature language use, they can express the emotional pain caused by group bullying through anxiety as opposed to somatization. ${ }^{33}$ This study does not enable identification of the causal relationship between depression/anxiety and bullying. However, previous research ${ }^{6,10,11}$ suggests that individuals with higher levels of depression and anxiety are more prone to being bullied and that bullying consequently increases the severity of depression and anxiety, creating a vicious cycle.

Children with depressive symptoms in the midst of toxic environments may have remission of some or many of their depressive symptoms when the stressors diminish. However, children with depressive symptoms often display irritability and withdrawal from their families, leading to devastating social isolation. ${ }^{43}$ These characteristics of children with depressive symptoms make it difficult for their guardians to consider visiting the hospital. Mood disorders that arise in childhood may be the most severe form of such disorders. Affected children also are likely to have such secondary complications as conduct disorders or substance abuse. ${ }^{6}$ Anxiety disorders and depressive disorders are among the most common disorders experienced by youth, and external life stresses probably intensify anxiety. Children with anxiety disorders are at increased risk for adult anxiety disorders, and anxious parents are at increased risk of having children with anxiety disorders. ${ }^{14}$ Bullying victims with depression or symptoms of anxiety symptoms should thus be treated with caution.

This study has several limitations. First, because the number of students surveyed was small and the sampling was not conducted across the country, the research findings may not be generalizable. It is generally true that children in childwelfare facilities belong to lower socioeconomic classes, 
but it should also be considered that individual students' situations may vary. Second, in this sample, $22 \%$ of lower graders and $12 \%$ of upper graders reported that they had been bullied. These rates are lower than those of a previous study of elementary-school students of average socioeconomic class, which found that $23 \%$ of lower graders and $20.3 \%$ of upper graders reported being victims of bullying. ${ }^{44}$ This discrepancy may be attributed to the fact that because the survey was conducted in the presence of a homeroom teacher and a researcher, the students surveyed may have been on the defensive. Additionally, the survey did not specify the time and duration of bullying. Third, although the criteria for school bullying used in this research have commonly been utilized in schools, the credibility and validity of these criteria have not yet been verified. The survey also did not classify bullies, victims, and bullies who were also victims according to the construct of peer bullying. This study classified participants into two groups: a bullying victims group and a normal group. These drawbacks limited the opportunity to observe the psychopathological differences between the two groups. However, internal consistency among the questionnaires is relatively good, and because this study used the cut-off score to divide groups based on whether the respondents have been bullied, the criteria may not have a critical effect on the analysis of the research findings. Fourth, all of the scales are self-reports and shared method variance may conflate the results.

This research has clinical significance because it involved elementary school students of low SES, a group known to be psychiatrically vulnerable, unlike previous studies on group bullying that included elementary school students of average SES. Moreover, this study is more meaningful because groups in different stages of personal development were compared and different aspects of group bullying were examined. $^{2}$

This study examined the differences in clinical characteristics and psychopathology related to group bullying among elementary school students using child-welfare facilities. In contrast to their peers, this group was found to be highly likely to be bullied. Individuals in lower grades had a greater tendency to suffer from somatization, depression, Internet addiction, and ADHD. The higher these individuals' levels of somatization and depression, the more likely they were to be bullied. The upper graders showed high scores in cognitive problems, depression, anxiety, ADHD, Internet addiction, and suicidal ideation. Above all, the more severe their anxiety, the more prone they were to being bullied. Consequently, elementary school students using child-welfare facilities are more psychiatrically vulnerable, which is highly likely to lead to group bullying. Victims of group bullying may suffer from mental problems that manifest in different forms according to age. Therefore, careful consideration of the above-mentioned characteristics is needed when developing mental-health screening questionnaires for elementary school students.

\section{Disclosure}

The authors report no conflicts of interest in this work.

\section{References}

1. Choi Y, Jhin H, Kim J. A study on the personality trait of bullying and victimized school children. J Child Adolesc Psychiatry. 2001;12(1): 94-102. Available from: http://www.riss.kr/link?id=A3014057. Accessed January 27, 2015. Korean.

2. Dawkins J. Bullying in schools: doctors' responsibilities. BMJ. 1995; 310(6975):274-275

3. Eslea M, Rees J. At what age are children most likely to be bullied at school? Aggress Behav. 2001;27(6):419-429.

4. Due P, Holstein BE, Lynch J, et al. Bullying and symptoms among school-aged children: international comparative cross sectional study in 28 countries. Eur J Public Health. 2005;15(2):128-132.

5. Kaltiala-Heino R, Rimpelä M, Marttunen M, Rimpelä A, Rantanen P. Bullying, depression, and suicidal ideation in Finnish adolescents: school survey. BMJ. 1999;319(7206):348-351.

6. Kwon SJ, Park TW, Park SH, Yang JC, Chung YC, Chung SK. Prevalence of School Bullying and Related Psychopathology in Children and Adolescents. J Korean Acad Child Adolesc Psychiatry. 2012; 23(3):143-153.

7. Kaltiala-Heino R, Rimpelä M, Marttunen M, Rimpelä A, Rantanen P. Bullying, depression, and suicidal ideation in Finnish adolescents: school survey. BMJ. 1999;319(7206):348-351.

8. Yang SJ, Kim JM, Kim SW, Shin IS, Yoon JS. Bullying and victimization behaviors in boys and girls at South Korean primary schools. $J$ Am Acad Child Adolesc Psychiatry. 2006;45(1):69-77.

9. Olweus D. Victimization by peers: Antecedents and long-term outcomes. In: Asendorpf JB, Rubin KH, editors. Social withdrawal, inhibition, and shyness in childhood. Hillsdale: Lawrence Erlbaum Associates, Inc; 1993:315-341.

10. Fekkes M, Pijpers FI, Fredriks AM, Vogels T, Verloove-Vanhorick SP. Do bullied children get ill, or do ill children get bullied? A prospective cohort study on the relationship between bullying and health-related symptoms. Pediatrics. 2006;117(5):1568-1574.

11. Nishina A, Juvonen J, Witkow MR. Sticks and stones may break my bones, but names will make me feel sick: The psychosocial, somatic, and scholastic consequences of peer harassment. J Clin Child Adolesc Psychol. 2005;34(1):37-48.

12. Kochenderfer BJ, Ladd GW. Peer victimization: cause or consequence of school maladjustment? Child Dev. 1996;67(4):1305-1317.

13. Kim YS, Leventhal BL, Koh YJ, Hubbard A, Boyce WT. School bullying and youth violence: causes or consequences of psychopathologic behavior? Arch Genl Psychiatry. 2006;63(9):1035-1041.

14. Kaplan HI, Sadock BJ. Synopsis of Psychiatry: Behavioral Science Clinical Psychiatry: Baltimore: Williams \& Wilkins Co; 1988.

15. icareinfo.info [homepage on the Internet]. Seoul: Headquarters for community child center, Inc.; [updated March 15, 2012; cited November 9, 2013]. Available from: https://www.icareinfo.info. Accessed November 24, 2014.

16. Kim SY, Ha JH, Hwang WS, Yu J. Association of Psychosocial Factors in Developing Childhood Depression and ADHD in a Community Low Income Family Children. J Korean Acad Child Adolesc Psychiatry. 2009;20(2):76-81. 
17. Tracy M, Zimmerman FJ, Galea S, McCauley E, Stoep AV. What explains the relation between family poverty and childhood depressive symptoms? J Psychiatric Res. 2008;42(14):1163-1175.

18. Essex MJ, Kraemer HC, Armstrong JM, et al. Exploring risk factors for the emergence of children's mental health problems. Arch Genl Psychiatry. 2006;63(11):1246-1256.

19. guidance.co.kr [homepage on the Internet]. Seongnam: Korea guidance, Inc.; [updated March 1, 2000; cited November 9, 2013]. Available from: http://www.guidance.co.kr/agMain/etest/eTest_03b.asp?FCode=04. Accessed November 24, 2014.

20. Huh Y, Ahn DH, Choi JH, Kang JY, Kim YY, Oh KJ. [Development of a Child Problem-Behavior Screening Test]. J Korean Neuropsychiatr Assoc. 2003;42(6):724-735. Korean.

21. Cho S, Lee Y. Development of the Korean form of the Kovacs' Children's Depression Inventory. J Korean Neuropsychiatr Assoc. 1990; 29(4):943-956. Korean.

22. Beck AT, Epstein N, Brown G, Steer RA. An inventory for measuring clinical anxiety: psychometric properties. J Consult Clin Psychol. 1988;56(6):893.

23. Yook S, Kim Z. A clinical study on the Korean version of Beck Anxiety Inventory: comparative study of patient and non-patient. Korean J Clin Psychol. 1997;16(1):185-197. Korean.

24. Song Y-M, Lee H-K, Kim JW, Lee K. [Reliability and Validity of the Korean Version of Beck Depression Inventory-II via the Internet: Results from a University Student Sample]. J Korean Neuropsychiatr Assoc. 2012;51(6):402-408. Korean.

25. Reynolds W. Manual for the Suicidal ideation questionnaire. Odessa, FL: Psychological Assessment Resources; 1988.

26. Gutierrez PM, Osman A. Getting the Best Return on Your Screening Investment: An Analysis of the Suicidal Ideation Questionnaire and Reynolds Adolescent Depression Scale. School Psych Rev. 2009;38(2):200-217.

27. Young KS. Caught in the net: How to recognize the signs of internet addiction - and a winning strategy for recovery. New York: John Wiley \& Sons; 1998.

28. Bahn G, Shin M, Cho S, Hong K. A preliminary study for the development of the assessment scale for ADHD in adolescents: reliability and validity for CASS-S. J Child Adolesc Psychiatry. 2001; 12(2):218-224. Korean.

29. Schwartz D, Dodge KA, Coie JD. The emergence of chronic peer victimization in boys' play groups. Child Dev. 1993;64(6):1755-1772.

30. Pellegrini AD, Long JD. A longitudinal study of bullying, dominance, and victimization during the transition from primary school through secondary school. Br J Dev Psychol. 2002;20(2):259-280.
31. Spriggs AL, Iannotti RJ, Nansel TR, Haynie DL. Adolescent bullying involvement and perceived family, peer and school relations: commonalities and differences across race/ethnicity. J Adolesc Health. 2007;41(3):283-293.

32. Bowes L, Arseneault L, Maughan B, Taylor A, Caspi A, Moffitt TE. School, neighborhood, and family factors are associated with children's bullying involvement: a nationally representative longitudinal study. J Am Acad Child Adolesc Psychiatry. 2009;48(5):545-553.

33. Chung KS. Children's somatic symptoms by emotion related child and parenting variables. Korean Assoc Child Stud. 2009;30(4):155-171. Korean.

34. Kim M, Kim K. Clinical Study of Somatization Disorder. Ment Health J. 1984;2(-):137-157. Korean.

35. Nansel TR, Overpeck M, Pilla RS, Ruan WJ, Simons-Morton B, Scheidt P. Bullying behaviors among US youth: prevalence and association with psychosocial adjustment. JAMA. 2001;285(16):2094-2100.

36. Ackerman BP, Kogos J, Youngstrom E, Schoff K, Izard C. Family instability and the problem behaviors of children from economically disadvantaged families. Dev Psychol. 1999;35(1):258-268.

37. Moon D, Lee J, LEE J, Kim J, Moon S. A Structural Relationship between the related Variables of Adolescence's Suicidal Ideation. Korean J Child Stud. 2013;34(3):93-112. Korean.

38. Sanders CE, Field TM, Diego M, Kaplan M. The relationship of Internet use to depression and social isolation among adolescents. Adolescence. 2000;35(138):237-242.

39. Shapira NA, Goldsmith TD, Keck PE Jr, Khosla UM, McElroy SL. Psychiatric features of individuals with problematic internet use. $J$ Affect Disord. 2000;57(1-3):267-272.

40. Choi WH, Son JW, Kim YR, et al. A Study of Covert Narcissism in Adolescent Internet Addiction: Relationshipto Anonymity, Presence, Interactivity, and Achievement Motivation. J Korean Acad Child Adolesc Psychiatry. 2011;22(2):103-111.

41. Schachar R, Logan GD. Impulsivity and inhibitory control in normal development and childhood psychopathology. Dev Psychol. 1990;26(5):710-720.

42. Yoo H, Woo S, Kim J, Ha J, Lee C, Sohn J. Relationship between Attention Deficit Hyperactivity Disorder Symptoms and Internet Addiction in High School Students. Korean J Psychopathol. 2003;12(1-2):85-94.

43. Kaplan HI, Sadock BJ. Synopsis of psychiatry: Behavioral sciences clinical psychiatry. Baltimore: Williams \& Wilkins Co; 1988.

44. Lee C, Kwak K. Group bullying in the school. 1st ed. Seoul: Jipmoondang; 2000.
Neuropsychiatric Disease and Treatment

\section{Publish your work in this journal}

Neuropsychiatric Disease and Treatment is an international, peerreviewed journal of clinical therapeutics and pharmacology focusing on concise rapid reporting of clinical or pre-clinical studies on a range of neuropsychiatric and neurological disorders. This journal is indexed on PubMed Central, the 'PsycINFO' database and CAS,
Dovepress

and is the official journal of The International Neuropsychiatric Association (INA). The manuscript management system is completely online and includes a very quick and fair peer-review system, which is all easy to use. Visit http://www.dovepress.com/testimonials.php to read real quotes from published authors. 